\title{
Early Detection of Students Suspected of Having Specific Disorders Learning and Designing Interventions (Executive Functions and Cognitive Processes)
}

\author{
Abolghasem Yaghoobi ${ }^{1 *}$ Maryam Palangi $^{2}$ \\ 1. Professor, Department of Psychology, Faculty of Economics and Social Sciences, University of Bu-Ali Sina, Hamedan, Iran \\ 2. Graduate of Clinical Psychology, Department of Psychology, Faculty of Literature and Humanities, Islamic Azad University, \\ Hamadan Branch, Iran \\ * Corresponding author's Email: yaghobi41@yahoo.com
}

\begin{abstract}
The aim of this study was to develop a tool for early detection of students who were suspected of having specific learning disabilities. Also, an educational program for students' intervention and education with learning disabilities was developed, and its validity was evaluated. In the first stage, a 75 questions inventory with yes and no responding scale was compiled and performed on 154 preschool girls and boys in the first and second districts of Hamadan in the academic year of 2020. The factor structure of the questionnaire was examined through confirmatory factor analysis by LISREL software. In the second stage, the final questionnaire was administered to the experimental group as a pre-test, which included twenty 6year-old preschool students with learning disabilities. After twelve sessions of training on executive functions and cognitive processes, the same questionnaire was administered as a post-test. Finally, the scores of both pre-test and post-test stages obtained from two control and experimental groups were compared by using univariate analysis of covariance (ANCOVA) and multivariate analysis of covariance (MANCOVA). The results of confirmatory factor analysis indicated that the questions of this scale, based on 13 existing factors, were apt to explain the structure of problems in children's learning in the research community. Therefore, Learning Disabilities Scale as a reliable and valid scale in Iranian society could be used by researchers in the fields of psychology and counseling. Furthermore, the results of analysis of covariance indicated that teaching and strengthening executive functions and cognitive processes such as memory, attention, perception and language skills had an effect on improving students' learning disabilities. According to the consequences, the intervention was effective on all cognitive, emotional and social attributes of students except the development of lateral dominance and the development of children's play.
\end{abstract}

Keywords: Students with specific needs, Specific Learning Disabilities, Early Interventions, Cognitive Processes, Executive Functions

\section{Introduction}

Learning can be considered a fundamental process as a result of which, a helpless creature, over time and in interaction with psychological and physical growth, reaches a person whose cognitive abilities and thinking power know no boundaries. Some people have problems in the normal process of learning. One group of these people are students with learning disabilities (Sobhigharamaleki, Abolghasemi, \& Dehghan, 2014). According to the Fifth edition of Diagnostic and Statistical Manual of Mental Disorders (DSM-5), learning disability has changed its name and nature to a specific learning disability so that the three mathematical disorders, reading disorder and writing disorder, each of which was previously considered an independent and separate disorder, are now considered as a specific area in a specific learning disorder. This disorder manifests itself in the form of learning difficulties and failure to acquire age-appropriate academic skills in the early years of education. These problems last for at least six 
months and are not related to mental disabilities or developmental or neurological or motor disorders. The prevalence of specific learning disabilities in reading, writing, and math is about $5-15 \%$ in primary school children in different cultures, and its prevalence in adults is estimated at about $4 \%$ (American Psychiatric Association, 2013).

Among family members, the mother is the first person who has a close relationship with the child, not only during the fetal period, but also in the afterlife, and among the many factors affecting human development in the child, the mother's personality and how she communicates is essential in the child development (Carnes-Holt, 2012).

Motherhood is a dynamic and stressful process, without any guidelines and dependent on culture and society. Achieving motherhood also requires knowledge, skills and motivation. Lack of knowledge, skills and motivation leads to deficits in maternal abilities and causes stress and anxiety (Jafarnejad, Azmoudeh, Mazloum, \& Reyhani, 2014). The presence of behavioral problems in children is an important predictor of maternal parental self-efficacy (Kuhn \& Carter, 2006) and causes parents, especially mothers, in their expectations and perceptions of how much they can be considered as a parent to act appropriately and effectively, and to what extent they are able to make a positive impact on their child's behavior, growth, and adjustment, and to feel high / low self-efficacy. Parental self-efficacy is an important cognitive structure that includes beliefs about success in parenting. Parental self-efficacy indicates how confident parents are in their ability to manage their child's problems. Low levels of parental self-efficacy often lead to depression and decreased satisfaction with parenting. Research has shown that parental self-efficacy is inversely related to children's behavioral problems (Jones \& Prinz, $\underline{2005}$ ).

Another important variable that mothers of exceptional children are involved with is cognitive regulation of emotion (Salimi, Mahdavi, Yeghaneh, Abedin, \& Hajhosseini, 2019). Managing and regulating emotion in individuals includes all conscious and unconscious strategies and helps the ability to understand emotions, adjust experience and express emotions. Any defect in emotion regulation can make a person vulnerable to mental disorders (Gravand \& Monshee, 2013). Emotional instability leads to inappropriate anger, chronic feelings of emptiness, mood swings, and frequent and intense responses to emotional stimuli. The emotional instability causes the mother to experience behavioral instability, poor control over her emotions, severe physiological arousal, and disruption of interpersonal relationships (Thghizadeh, Ghorbani, \& Saffarinia, 2015). Learning disabilities may affect a mother's acceptance of a child with these disorders, whereas in all children adopted by parents, they are more likely in adulthood to have behavioral adaptations (greater independence, higher self-esteem, low level aggression and more positive self-sufficiency) and children who are rejected by their parents are more likely to be associated with behavioral maladaptation (high level aggression, suicide, depression, antisocial behavior, dropout, and delinquency) into adulthood (Rohner \& Khaleque, 2010). Parent-child interaction is a complex and multidimensional phenomenon and due to the interaction of several factors such as parental attitude and acceptance, how to manage and control behavior, sense of social competence and self-control, parenting knowledge and skills and self-confidence of parents in rearing 
children and creating an environment with minimal conflict are formed (Pourmohamadreza Tajrishi, Ashouri, Afrooz, Arjmandnia, \& Ghobari Bonab, 2015). Gaining a proper understanding and acceptance of children's behavior can predict parents 'empathy with children and their correct perception of parents' behavioral problems. Increasing parental acceptance and the child's perception of being accepted in relation to parents can be effective in reducing children's behavioral problems (Mostafavi, Shaeeri, Asghari Moghaddam, \& Mahmoudi Charaie, 2013). The ability to manage a mother's emotions is one of the factors that can be improved through education. Mothers who have a high ability to regulate emotion and understand their child's moods have more abilities in performing motherly duties (Golchin \& Hosseini-Nasab, 2013).

Behavioral scientists believe that one of the most effective programs that help people to have a better and healthier life is the communication skills training program. The purpose of this program is to help people to know themselves better and to establish appropriate and effective interpersonal relationships and to solve people's problems as best as possible. In the shadow of achieving such a goal, the sociopsychological ability of the individual increases. By improving the social abilities of individuals in a society, the level of mental health of the society can be increased and the occurrence of social harms can be prevented. Sadri Damirchi, Asadi Shishegaran, and Esmaili Ghazivaloii (2016), in a study entitled the effectiveness of social-emotional skills training on cognitive emotion regulation and social skills in children with special learning disabilities, concluded that there is a significant difference between the two groups in the components of cognitive emotion regulation (positive and negative). Also, there was a significant difference between the two groups in the components of social-emotional skills in increasing the use of positive emotional strategies and improving appropriate social skills, selfconfidence and relationships with peers. Ghaemi, Soltaninejad, and Khaje (2018), in a study entitled predicting quality of life based on cognitive emotion regulation strategies and communication skills in nurses, revealed a positive and significant relationship between cognitive emotion regulation strategies and communication skills with quality of life. The results showed that cognitive emotion regulation strategies and communication skills predict $48 \%$ of the variance of the psychological dimension and $39 \%$ of the variance of the physical dimension of quality of life. (Varasteh, Aslani, \& Amanelahi, 2017), in a study entitled the effectiveness of positive parenting program training on the quality of parent-child interaction, indicated that there was a significant difference between the experimental and control groups at least in one of the three factors including the proximity, dependence and overall positive relationship. Olivares-Olivares, Ortiz-González, and Olivares (2019) in their study investigated the effect of social skills training on social anxiety disorder. In this study that 108 adolescents participated with a diagnosis of generalized social anxiety, the subjects were randomly assigned to two groups (with and without social skills training). The results showed that social skills training reduces the rate of withdrawal from the intervention and increases the effectiveness of treatment programs.

According to the research literature and the results of previous studies, in this study, the effect of emotional-communication skills training in mothers of children with learning disabilities on parental self-efficacy, cognitive emotion regulation and parental acceptance was examined. Accordingly, the 
present study sought to answer the question of whether communication-emotional skills training can lead to increased self-efficacy, emotional regulation and parental acceptance in mothers of children with learning disabilities?

\section{Material and Methods}

This study consisted of two main objectives, so it was conducted in two main sections. The research method in the first part related to the construction and tool development, was a descriptive survey method, and the second part related to the effectiveness of the educational intervention was performed semi-experimentally with a pre-test and post-test design in a control group. The design diagram in question is as follows:

Diagram1. Research Model

\begin{tabular}{ccccr}
\hline Groups & Random assignment & Pretest & IV & Posttest \\
\hline $\begin{array}{c}\text { Experimental } \\
\text { group }\end{array}$ & $\mathrm{R}$ & $\mathrm{T} 1$ & $\mathrm{X}$ & $\mathrm{T} 2$ \\
Control group & $\mathrm{R}$ & $\mathrm{T} 1$ & - & $\mathrm{T2}$ \\
\hline
\end{tabular}

The statistical population of the study included all preschool girls and boys in the first and second districts of Hamadan who were studying in 2020 academic year. In order to select the sample, six centers were selected from preschool centers. Twenty-five students were randomly selected from each center, for a total of 154 people, and then a researcher-made screening questionnaire was administered to them. In the second part of the study-the educational intervention, 40 students who scored low on the researcher-made screening questionnaire were randomly selected from four preschool centers, and 20 of them were assigned to the experimental group and the rest of 20 students for the control group. The following questionnaires were used to collect data:

1. Revised Wechsler IQ Scale for Children (WISC-R): This scale has 12 subtests, 6 verbal subtests and 6 non-verbal or practical subtests, of which 2 subtests were mazes and numerical memory as supplemental subtests. The validity and reliability of this scale have been confirmed in previous studies (Canivez, Watkins, Good, James, \& James, 2017; Razavieh \& Shahim, 1992). In the present study, this scale was used to meet the inclusion criteria (IQ above 85).

2. Researcher-made screening questionnaire: This questionnaire consisted of 75 questions, the answers had two options, yes and no. This questionnaire was developed based on diagnostic symptoms in different theories about the characteristics and types of L.D. children. If the student has the desired feature in each question, he / she will be awarded 1 point; if he / she does not have that feature, he / she will be awarded 0 points. Finally, the sum of the scores of the questions determined the person's score 
in the questionnaire. The minimum score that a person got in the questionnaire was zero, indicated the existence of a learning disability, and the highest score that a person may receive from the questionnaire is 75 , indicated the absence of a learning disability. This scale also included 7 subscales by which the information was presented in Table 1. A cut-off score was also determined to diagnose and identify children with learning disabilities. To determine the cut-off score, 20 children with learning disabilities were first identified. To identify these children, WISC-R test, clinical observations of educators and parents' reports were used. After identifying children with learning disabilities, a researcher-made scale was performed on them. Finally, the cut-off score for diagnosing learning disabilities in children was specified as 45-40. This means that students who receive a score of approximately 40 or 45 out of a total score of 75 in the screening form were suspected of having a learning disability. The more their acquired score reduced from 40-45 to zero, the more they were likely to have learning disability. In this study, in order to evaluate the validity of the questionnaire along with the opinions of educators, professors and experts in this field, confirmatory factor analysis was used, and to evaluate the reliability, Cronbach's alpha internal consistency method was used.

Table 1: Components and questions related to the screening questionnaire for students with suspected learning disabilities

\begin{tabular}{|l|l|}
\hline \multicolumn{1}{|c|}{ Components } & \multicolumn{1}{|c|}{ Items } \\
\hline Self-management skills and the child's sense of independence & $1,2,3$ \\
\hline Gross motor activities & $15,14,16,66,67$ \\
\hline Fine motor activities & $17,13,12,11,18,19,23$ \\
\hline Auditory memory and knowledge of the phonological structure & $31,32,34,36,35,38,43,70,69,68$ \\
\hline Visual memory & $285,29,30,51,59,58,60$ \\
\hline Linguistic and communication activities & $54,26,55,56,57,65,70,71,72,73,74,75$ \\
\hline Accuracy and attention & $20,21,22,23,24,25,35,37$ \\
\hline
\end{tabular}

In this study, the participants of the experimental group, during one month, 12 one-hour sessions, three sessions per week were taught the training of executive functions and cognitive processes such as selfmanagement skills, cognitive skills, motor skills, perceptual skills, social skills, etc. by instructors and parents. A summary of the treatment protocol was provided in Table 2.

Table 2. Summary of treatment protocol

\begin{tabular}{|l|l|l|}
\hline Session & $\begin{array}{l}\text { Components of learning } \\
\text { disabilities }\end{array}$ & Therapeutic strategies \\
\hline 1 & $\begin{array}{l}\text { Justify the coaches and provide } \\
\text { the necessary training to the } \\
\text { coaches }\end{array}$ & $\begin{array}{l}\text { Problem solving, justifying educators to strengthen the necessary skills in a } \\
\text { child suspected of special learning difficulties and providing the necessary } \\
\text { training to educators }\end{array}$ \\
\hline 2 & $\begin{array}{l}\text { Strengthen self-management } \\
\text { skills and achieve self-concept }\end{array}$ & $\begin{array}{l}\text { The child achieves self-care or self-control through activities such as } \\
\text { dressing, eating, and personal hygiene. }\end{array}$ \\
\hline
\end{tabular}




\begin{tabular}{|c|c|c|}
\hline 3 & $\begin{array}{l}\text { Strengthen self-management } \\
\text { skills and a sense of } \\
\text { independence }\end{array}$ & $\begin{array}{l}\text { By acquiring self-governing skills, the child increases the positive } \\
\text { development of self-concept and a sense of independence. }\end{array}$ \\
\hline 4 & $\begin{array}{lll}\begin{array}{l}\text { Strengthen } \\
\text { activities }\end{array} & \text { gross } & \text { motor } \\
\end{array}$ & The child is asked to do activities such as jumping, swinging and climbing \\
\hline 5 & Enhance fine motor activities & $\begin{array}{l}\text { Doing some activities such as: opening the buttons and opening and closing } \\
\text { the shoelaces, needle threading and painting }\end{array}$ \\
\hline 6 & $\begin{array}{l}\text { Strengthen auditory memory } \\
\text { and awareness of phonological } \\
\text { structure and strengthen } \\
\text { working memory }\end{array}$ & $\begin{array}{l}\text { The child is asked to do activities such as: practicing loud and short voices } \\
\text { to distinguish between them, practicing understanding the meanings of the } \\
\text { story and completing an unfinished story, and so on. }\end{array}$ \\
\hline 7 & $\begin{array}{l}\text { Strengthen auditory memory } \\
\text { and awareness of phonological } \\
\text { structure }\end{array}$ & $\begin{array}{l}\text { Performing activities that can help the child recognize sounds, distinguish } \\
\text { between auditory sounds, and enhance auditory memory include word } \\
\text { games, rhyming games, and word memorization games. } \\
\text { Listening and recognizing surrounding sounds: rain, the sound of horse } \\
\text { poison, animal sounds, heartbeat, sirens, horns, etc. } \\
\text { - Clean sound far and near } \\
\text { - Clean short and loud sound } \\
\text { - Identify the recorded sounds of birds, objects, occupations, activities, etc. }\end{array}$ \\
\hline $8 \& 9$ & $\begin{array}{l}\text { Enhance visual memory, } \\
\text { accuracy and attention }\end{array}$ & $\begin{array}{l}\text { Recognizing differences and similarities in images, shapes, and letters were } \\
\text { activities that transform visual differentiation, visual memory, and visual- } \\
\text { motor integration (such as eye-hand coordination). Performing activities } \\
\text { such as taking pictures, painting, picking shapes, copying shapes, shooting } \\
\text { with a plastic gun, walking between lines, etc. }\end{array}$ \\
\hline 10 & $\begin{array}{l}\text { Linguistic and communication } \\
\text { activities }\end{array}$ & $\begin{array}{l}\text { make a picture story with simple sentences for the child and try to use stories } \\
\text { in which the pronoun "we" is used. Then we ask the child to tell the story to } \\
\text { us. }\end{array}$ \\
\hline 11 & $\begin{array}{l}\text { Linguistic and communication } \\
\text { activities }\end{array}$ & Ask the child to read picture books to us \\
\hline 12 & Social activities & $\begin{array}{l}\text { play group games to strengthen children's social skills, use group activities } \\
\text { and listen to others }\end{array}$ \\
\hline
\end{tabular}

\section{Results}

Descriptive statistics and inferential statistics were used to analyze the obtained data. Descriptive statistics were used to calculate mean and standard deviation. Confirmatory factor analysis was used to evaluate the validity of the questionnaire, and multivariate analysis of covariance (MANCOVA) was used to test the research hypotheses. Prior to MANCOVA implementation, its assumptions including normality, homogeneity of variance, homogeneity of interactive effects and homogeneity of regression slopes were tested and confirmed. The goodness-of-fit indexes of the confirmatory factor analysis of the Child Learning Disabilities Diagnosis Scale were reported in Table 3.

Table 3. Goodness-of-fit indexes of the confirmatory factor analysis of the Child Learning Disabilities Diagnosis Scale

\begin{tabular}{|l|l|}
\hline \multicolumn{1}{|l|}{ Index } & Value \\
\hline Chi-square to freedom ratio (X $\left.\mathrm{X}^{2} \mathrm{df}\right)$ & 2.05 \\
\hline Root mean square error of approximation (RMSEA) & .078 \\
\hline Good Fit Index (GFI) & .96 \\
\hline Adjusted Good Fit Index (AGFI) & .93 \\
\hline Comparative fit index (CFI) & .95 \\
\hline Normed Fit Index (NFI) & .93 \\
\hline
\end{tabular}


Early Detection of Students Suspected of Having Specific Disorders Learning and Designing Interventions...

NonNormed Fit Index (NNFI)

.91

The indicators reported in Table 3 show that the model had a good validity. Therefore, the Child Learning Disabilities Diagnosis Scale in the target community had a good validity, and the questions of this scale can explain the desired structure. Table 4 shows the factor loads of the questions and their coefficient of determination. Also, the reliability of questionnaire subscales was presented in Table 4.

Table 4. Psychometric Properties of Child Learning Disabilities Diagnosis Scale Items

\begin{tabular}{|c|c|c|c|c|c|c|c|}
\hline Factor & Items & $\begin{array}{l}\text { Loading } \\
\text { factor }\end{array}$ & $\mathrm{R}^{2}$ & $\begin{array}{c}\text { Std. } \\
\text { Error }\end{array}$ & $\begin{array}{c}\mathrm{T} \\
\text { value }\end{array}$ & $\begin{array}{l}\text { Correlation with } \\
\text { total score }\end{array}$ & $\begin{array}{c}\text { Alpha if item } \\
\text { deleted }\end{array}$ \\
\hline \multirow{3}{*}{$\begin{array}{l}\text { Physical development and self-help } \\
\text { in children }\end{array}$} & 1 & .30 & .59 & .04 & 7.92 & .33 & .41 \\
\hline & 2 & .15 & .18 & .03 & 4.67 & .38 & .32 \\
\hline & 3 & .11 & .10 & .03 & 3.48 & .27 & .49 \\
\hline \multirow[t]{2}{*}{ Lateral dominance maturation } & 4 & .02 & .00 & .01 & 1.72 & .15 & .26 \\
\hline & 5 & 1.20 & .63 & .41 & 2.92 & .15 & .26 \\
\hline \multirow{5}{*}{ Perception of motor skills } & 6 & .14 & .18 & .03 & 4.89 & .27 & .58 \\
\hline & 7 & .16 & .41 & .02 & 7.65 & .38 & .51 \\
\hline & 8 & .14 & .26 & .02 & 5.94 & .35 & .52 \\
\hline & 9 & .06 & .09 & .02 & 3.41 & .37 & .53 \\
\hline & 10 & .11 & .20 & .02 & 5.07 & .38 & .51 \\
\hline \multirow{3}{*}{ Painting ability development } & 11 & .28 & .60 & .03 & 8.80 & .46 & .35 \\
\hline & 12 & .29 & .41 & .04 & 7.41 & .44 & .33 \\
\hline & 13 & .16 & .12 & .04 & 3.75 & .24 & .67 \\
\hline \multirow{5}{*}{ Development of gross motor skills } & 14 & .15 & .14 & .03 & 4.35 & .29 & .40 \\
\hline & 15 & .15 & .22 & .03 & 5.47 & .37 & .36 \\
\hline & 16 & .08 & .02 & .04 & 1.79 & .16 & .50 \\
\hline & 66 & .18 & .37 & .02 & 7.56 & .30 & .40 \\
\hline & 67 & .28 & .32 & .04 & 6.61 & .24 & .44 \\
\hline \multirow{3}{*}{ Development of fine motor skills } & 17 & .27 & .39 & .05 & 5.95 & .25 & .14 \\
\hline & 18 & .19 & .28 & .04 & 5.38 & .17 & .08 \\
\hline & 19 & .03 & .00 & .04 & .63 & -.007 & .49 \\
\hline \multirow{7}{*}{$\begin{array}{l}\text { Attention development and } \\
\text { attention deficit in children }\end{array}$} & 20 & .17 & .15 & .04 & 4.61 & .29 & .72 \\
\hline & 22 & .30 & .40 & .04 & 5.15 & .57 & .64 \\
\hline & 23 & .20 & .32 & .03 & 7.11 & .37 & .70 \\
\hline & 24 & .30 & .45 & .03 & 8.80 & .63 & .62 \\
\hline & 25 & .23 & .33 & .03 & 7.29 & .49 & .67 \\
\hline & 35 & .12 & .19 & .02 & 5.23 & .33 & .70 \\
\hline & 37 & .16 & .19 & .03 & 5.35 & .32 & .71 \\
\hline \multirow{4}{*}{ Memory } & 21 & .10 & .15 & .02 & 4.86 & .24 & .31 \\
\hline & 27 & .15 & .22 & .03 & 5.72 & .33 & .20 \\
\hline & 33 & .15 & .14 & .03 & 4.76 & .15 & .41 \\
\hline & 39 & .13 & .13 & .03 & 4.61 & .16 & .38 \\
\hline \multirow{8}{*}{$\begin{array}{l}\text { Auditory perception and memory } \\
\text { and auditory sensitivity }\end{array}$} & 31 & .19 & .23 & .03 & 6.02 & .35 & .52 \\
\hline & 32 & .10 & .05 & .04 & 2.77 & .18 & .59 \\
\hline & 34 & .07 & .10 & .02 & 3.85 & .34 & .54 \\
\hline & 36 & .21 & .22 & .04 & 5.92 & .25 & .57 \\
\hline & 38 & .07 & .13 & .01 & 4.53 & .23 & .57 \\
\hline & 68 & .10 & .14 & .02 & 4.68 & .29 & .55 \\
\hline & 69 & .12 & .15 & .02 & 4.82 & .43 & .50 \\
\hline & 70 & .18 & .30 & .03 & 7 & .34 & .53 \\
\hline \multirow{7}{*}{$\begin{array}{l}\text { Cognitive, expressive and Language } \\
\text { development }\end{array}$} & 40 & .28 & .43 & .03 & 8.81 & .57 & .72 \\
\hline & 41 & .24 & .33 & .03 & 7.43 & .48 & .73 \\
\hline & 42 & .28 & .40 & .03 & 8.44 & .48 & .73 \\
\hline & 44 & .06 & .06 & .02 & 2.86 & .21 & .75 \\
\hline & 45 & .01 & .00 & .01 & .66 & .10 & .76 \\
\hline & 46 & .07 & .03 & .03 & 2.16 & .09 & .76 \\
\hline & 47 & .10 & .25 & .02 & 6.37 & .35 & .75 \\
\hline
\end{tabular}




\begin{tabular}{|c|c|c|c|c|c|c|c|}
\hline & 48 & .05 & .06 & .02 & 2.96 & .19 & .75 \\
\hline & 49 & .17 & .18 & .03 & 5.24 & .34 & .74 \\
\hline & 50 & .21 & .28 & .03 & 6.73 & .45 & .74 \\
\hline & 52 & .15 & .21 & .03 & 5.77 & .44 & .74 \\
\hline & 53 & .07 & .02 & .04 & 1.78 & .19 & .76 \\
\hline & 54 & .16 & .13 & .04 & 4.38 & .33 & .75 \\
\hline & 61 & .09 & .11 & .02 & 4.11 & .33 & .75 \\
\hline & 62 & .11 & .20 & .02 & 5.66 & .39 & .74 \\
\hline & 71 & .12 & .10 & .03 & 3.91 & .27 & .75 \\
\hline & 72 & .22 & .19 & .04 & 5.50 & .42 & .74 \\
\hline & 73 & .17 & .12 & .04 & 4.28 & .37 & .74 \\
\hline & 74 & .14 & .08 & .04 & 3.43 & .23 & .76 \\
\hline & 75 & .16 & .11 & ד4 & 4 & .25 & .75 \\
\hline \multirow{6}{*}{ Perception and visual memory } & 28 & .15 & .25 & .02 & 6.17 & .27 & .46 \\
\hline & 29 & .12 & .13 & .03 & 4.44 & .32 & .44 \\
\hline & 30 & .09 & .09 & .03 & 3.69 & .36 & .42 \\
\hline & 51 & .13 & .08 & .04 & 3.51 & .22 & .51 \\
\hline & 58 & .10 & .15 & .02 & 4.83 & .27 & .47 \\
\hline & 59 & .13 & .19 & .02 & 5.37 & .20 & .50 \\
\hline \multirow[t]{2}{*}{ Play development } & 63 & .17 & .15 & .04 & 3.96 & .20 & .33 \\
\hline & 64 & .23 & .28 & .05 & 4.87 & .20 & .33 \\
\hline \multirow{4}{*}{ Socio-emotional development } & 55 & .19 & .21 & .04 & 5.28 & .30 & .56 \\
\hline & 56 & .22 & .30 & .03 & 6.46 & .40 & .48 \\
\hline & 57 & .12 & .17 & .03 & 4.69 & .32 & .54 \\
\hline & 65 & .27 & .43 & .04 & 7.68 & .44 & .43 \\
\hline
\end{tabular}

Multivariate analysis of covariance (MANCOVA) was used to analyze the main research hypothesis. The hypothesis of executive functions and cognitive processes training had a significant effect on the cognitive, perceptual, social and emotional dependent variables, from the four statistics of Hotelling's Trace; Wilk's Lambda, Pillai's Trace and Roy's Largest Root, Wilk's Lambda was reported in Table 5. In order to examine the effect of executive functions and cognitive processes training on every dependent variable, analysis of covariance (ANCOVA) embedded in MANCOVA was used. The results were presented in Table 6.

Table 5. Results of Wilk's Lambda on the scores of dependent variables

\begin{tabular}{|c|c|c|c|c|c|c|c|}
\hline Test & Value & F & $\begin{array}{c}\text { Df } \\
\text { Hypothesis }\end{array}$ & Error DF & P & Eta & Power \\
\hline Wilk's Lambda & .07 & 16.15 & 12 & 15 & .001 & .93 & .99 \\
\hline
\end{tabular}

Table 6. Results of Analysis of covariance (ANCOVA)

\begin{tabular}{|c|c|c|c|c|c|c|c|}
\hline Variable & SS & DF & MS & $\mathbf{F}$ & $p$ & Eta & Power \\
\hline Physical development and self-help in children & 4.11 & 1 & 4.11 & 7.17 & .01 & .22 & .73 \\
\hline Development of lateral dominance in children & .10 & 1 & .10 & .37 & .54 & .01 & .09 \\
\hline Perceptual-motor perception & 6.36 & 1 & 6.36 & 9.97 & .004 & .28 & .85 \\
\hline The development of painting ability in children & 5.69 & 1 & 5.69 & 16.86 & .001 & .40 & .97 \\
\hline Development of gross motor skills & 20.62 & 1 & 20.62 & 46.72 & .001 & .65 & 1 \\
\hline Develop fine motor skills & 3.25 & 1 & 3.25 & 25.32 & .001 & .50 & .99 \\
\hline Attention development and attention deficit in children & 30.89 & 1 & 30.89 & 25.58 & .001 & .53 & .99 \\
\hline Memory & 4.94 & 1 & 4.94 & 9.41 & .005 & .27 & .83 \\
\hline $\begin{array}{l}\text { Development of auditory perception and memory and auditory } \\
\text { sensitivity }\end{array}$ & 18.04 & 1 & 18.04 & 17.06 & .001 & .40 & .97 \\
\hline Cognitive, expressive and language development & 180.85 & 1 & 180.85 & 106.09 & .001 & .80 & 1 \\
\hline
\end{tabular}




\begin{tabular}{|c|c|c|c|c|c|c|c|}
\hline Development of perception and visual memory & 15.93 & 1 & 15.93 & 12.16 & .002 & .32 & .91 \\
\hline Play development & .60 & 1 & .60 & 2.54 & .12 & .09 & .33 \\
\hline Social-emotional development & 15.67 & 1 & 15.67 & 42.16 & .001 & .62 & 1 \\
\hline
\end{tabular}

According to Table 6, executive functions and cognitive processes training was effective on physical development and self-help in children, perceptual-motor perception, painting development in children, development of gross motor skills, fine motor skills development, development of attention and attention deficit in children, memory, perception and memory, auditory and auditory sensitivity, cognitive development, speech and language perception, visual perception and memory and socio-emotional development significantly $(p<.05)$. According to Table 6 , the intervention was not effective on the development of lateral dominance in children and the development of children's play.

\section{Discussion}

LD students were unable to read textbooks due to their difficulties and therefore face academic failure, which predisposes the individual to psychological problems and incurs unnecessary expenses for the family (Brigham, Scruggs, \& Mastropieri, 2011). Therefore, setting realistic expectations led to proper planning and goal setting. It was the basis of methods that were used to increase educational and family assistance to the child. The cryptic and contradictory nature of learning disorders had challenged various approaches to the intervention and treatment of these conditions (Narimani, 2016). Therefore, in order to achieve these realistic expectations, there was an urgent need for accurate measurement tools.

Findings showed that a researcher-made screening questionnaire consisting of 13 factors had the ability to explain the structure of problems and learning's children in the research community. Therefore, the Learning Disabilities Scale as a reliable and valid scale in Iranian society could be used by researchers in the fields of psychology and counseling and also as a valid tool. This tool can be useful for screening and rapid identification of students with specific learning disabilities, especially in educational situations. In fact, early assessment of these disorders could facilitate the course of treatment and ultimately increase the performance of students in the educational environment.

Also, the results of covariance analysis in evaluating the effectiveness of educational intervention in improving learning disabilities with special learning problems revealed that executive functions and cognitive processes training had an effect on improving learning disabilities of learners. Furthermore, the training did not have a significant effect only on the development of lateral dominance and the development of children's play. The results of this study were consistent with the results of past studies (Boustanzar \& Rezayi, 2017; Fernell et al., 2011; Lopes, 2005). These studies had shown that early 
intervention could enhance gross motor skills, visual memory, accuracy, attention, memory, concentration, social activities, language and communication activities in LD children.

In the field of diagnosis of learning disorders, the NEPSY test (Abedi, Malekpour, Oraizi, Faramarzi, \& Jamali Paghale, 2012) had also been standardized for this purpose. It identifies specific neuropsychological processes with executive / attention deficits, language, sensory-motor functions, visual-spatial processing, and memory and learning paved the way for early intervention, especially since neuropsychological / developmental impairments were prerequisites of academic skills in primary school. Although preschoolers with learning disabilities had not yet involved in academic learning tasks, they often had preconceived notions of academic failure. Children with learning disabilities often had deficiencies in phonology, the ability to analyze and combine sounds, rapid naming skills, learning the names and sounds of the alphabet, visual-motor coordination, and visual-perceptual coordination (Fletcher, Lyon, Fuchs, \& Barnes, 2018).

Numerous studies have shown that early detection and intervention of the neuropsychology was effective in rehabilitating and improving executive functions and attention in young children with learning disabilities. Recent research had shown the effectiveness of physical activity and rhythmic exercise on memory and learning. Studies showed that there was a positive relationship between play and attention improvement, planning skills and attitudes, creativity and thought-orientation (Bayat,

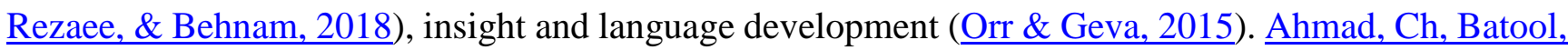
$\underline{\text { Sittar, and Malik (2016) }}$ stated that there was a strong relationship between play and cognitive development. Findings of Momeni and Bahrami (2002) had also confirmed the effectiveness of Dela Cato Neuropsychological Method on improving children's performance.

In explaining the lack of effect of educational intervention on the play development and the growth of lateral dominance, the cause could be attributed to the unreliability of questions related to these two components. In fact, it was possible that the training was effective, but the questions could not measure these two factors, because they did not have good reliability. If these questions were corrected and changed, a significant result could probably have been seen.

Consistently, Kesler, Lacayo, and Jo (2011) concluded that providing an educational approach led to increased activity of the prefrontal cortex and improved the speed of information processing and cognitive flexibility of these learners. The results of Stevens, Slavin, and Farnish (1991) research showed that children with poor education did not have the necessary knowledge about the goals, strategies and characteristics of the task; more importantly, even they had some knowledge, they could not monitor it. According to the Slavin (2019), children with learning disabilities might have problems in the metacognitive aspects of learning. 
In the end, it should be said that if we were to achieve the maximum result and maximum improvement of the disorder, it was necessary to adopt a special educational method according to the individual differences of each child, accurate analysis of the disorder, definition of functional goals and simultaneous treatment of process disorders. Of course, no treatment in a limited time could completely solve learning disorders, and for this purpose, long-term programs with exercise at home and school seemed necessary. One of the limitations that the researcher faced was the limited time of the intervention, and it was suggested that the intervention be performed continuously for a longer period of time. Especially if the intervention started at an early age, it would prevent learning difficulties during the early education period.

Conflict of interest: The authors state no conflict of interest in the study.

Financial sponsor: The authors acknowledge that they have not received any financial support for all stages of the study, writing and publication of the paper.

Acknowledgment: We hereby appreciate all the participants of the study as well as all those participating in the implementation of this project.

\section{References}

Abedi, A., Malekpour, M., Oraizi, H., Faramarzi, S., \& Jamali Paghale, S. (2012). Standardization of the neuropsychological test of nepsy on 3-4 years old children. Iranian Journal of Psychiatry and Clinical Psychology, 18(1), 52-60.

Ahmad, S., Ch, A. H., Batool, A., Sittar, K., \& Malik, M. (2016). Play and Cognitive Development: Formal Operational Perspective of Piaget's Theory. Journal of Education and Practice, 7(28), 72-79.

American Psychiatric Association, A. (2013). Diagnostic and statistical manual of mental disorders (DSM-5®): American Psychiatric Pub.

Bayat, F., Rezaee, A. M., \& Behnam, B. (2018). Comparison of the effectiveness of play therapy and storytelling on the improvement of Attention Deficit/Hyperactivity Disorder symptoms in students. Qom University of Medical Sciences Journal, 12(8), 59-68.

Boustanzar, R., \& Rezayi, S. (2017). Developing intervention program focused and divided attention and investigating its effectiveness on working memory IQ in children with specific learning disorder. JOURNAL OF LEARNING DISABILITIES, 7(1), 7-25.

Brigham, F. J., Scruggs, T. E., \& Mastropieri, M. A. (2011). Science education and students with learning disabilities. Learning Disabilities Research \& Practice, 26(4), 223-232.

Canivez, G. L., Watkins, M. W., Good, R., James, K., \& James, T. (2017). Construct validity of the Wechsler Intelligence Scale for Children-Fourth UK Edition with a referred Irish sample: Wechsler and Cattell-Horn-Carroll model comparisons with 15 subtests. British Journal of Educational Psychology, 87(3), 383-407.

Carnes-Holt, K. (2012). Child-parent relationship therapy for adoptive families. The Family Journal, 20(4), 419-426. 
Fernell, E., Hedvall, Å., Westerlund, J., Carlsson, L. H., Eriksson, M., Olsson, M. B., . . Gillberg, C. (2011). Early intervention in 208 Swedish preschoolers with autism spectrum disorder. A prospective naturalistic study. Research in developmental disabilities, 32(6), 2092-2101.

Fletcher, J. M., Lyon, G. R., Fuchs, L. S., \& Barnes, M. A. (2018). Learning disabilities: From identification to intervention: Guilford Publications.

Ghaemi, F., Soltaninejad, M., \& Khaje, F. (2018). The Prediction of Quality of life Based on Cognitive Emotion Regulation Strategies and Communication Skills in Female Nurses. Iranian Journal of Psychiatric Nursing, 6(5), 50-56.

Golchin, R., \& Hosseini-Nasab, S. D. (2013). A comparison of children's behavior problems among mothers with high and low emotional intelligence. Journal of Instruction and Evaluation, 6(24), 1324.

Gravand, P., \& Monshee, A. (2013). The effectiveness of teaching forgiveness based on Enright model and enriching the relationships on mental wellbeing and life quality of dissatisfied women from their marital life in the city of Khoram Abad. Middle Eastern Journal of Disability Studies, 2(12), 29-36.

Jafarnejad, F., Azmoudeh, E., Mazloum, S. R., \& Reyhani, T. (2014). The Effect of Self-Efficacy Training Package on Maternal Self-Confidence of Primiparous Women in Infant Care. The Iranian Journal of Obstetrics, Gynecology and Infertility, 17(104), 18-28. doi:10.22038/ijogi.2014.3021

Jones, T. L., \& Prinz, R. J. (2005). Potential roles of parental self-efficacy in parent and child adjustment: A review. Clinical psychology review, 25(3), 341-363.

Kesler, S. R., Lacayo, N. J., \& Jo, B. (2011). A pilot study of an online cognitive rehabilitation program for executive function skills in children with cancer-related brain injury. Brain Injury, 25(1), 101112.

Kuhn, J. C., \& Carter, A. S. (2006). Maternal self-efficacy and associated parenting cognitions among mothers of children with autism. American Journal of Orthopsychiatry, 76(4), 564-575.

Lopes, J. (2005). Intervention with students with learning, emotional and behavioral disorders: why do we take so long to do it? Education and Treatment of children, 345-360.

Momeni, F., \& Bahrami, H. (2002). An Evaluation of the Efficiency of Dela Cato Neuropsychological Method in Treatment of Hyperactive Children. Iranian Journal of Psychiatry and Clinical Psychology, 7(4), 73-78.

Mostafavi, S., Shaeeri, M. R., Asghari Moghaddam, M. A., \& Mahmoudi Charaie, J. (2013). Effectiveness Of Educating Play Therapy Based On Child Parent Relationship Therapy (Cprt) According Landreth Model To Mothers On Reducing Child Behavioral Problems. CLINICAL PSYCHOLOGY \& PERSONALITY (DANESHVAR RAFTAR), 19(7), 33-42.

Narimani, M. (2016). Comparison of negative mood and emotional expression in students with and without specific learning disorder. jiera, 9(31), 69-90.

Olivares-Olivares, P. J., Ortiz-González, P. F., \& Olivares, J. (2019). Role of social skills training in adolescents with social anxiety disorder. International journal of clinical and health psychology, 19(1), 41-48.

Orr, E., \& Geva, R. (2015). Symbolic play and language development. Infant behavior and development, $38,147-161$.

Pourmohamadreza Tajrishi, M., Ashouri, M., Afrooz, G. A., Arjmandnia, A. A., \& Ghobari Bonab, B. (2015). The Effectiveness Of Positive Parenting Program (Triple-P) Training On Interaction Of Mother-Child With Intellectual Disability. ARCHIVES OF REHABILITATION (JOURNAL OF REHABILITATION), 16(2), 128-136.

Razavieh, A., \& Shahim, S. (1992). A short form of the Wechsler Preschool and Primary Scale of Intelligence for use in Iran. Psychological reports, 71(3), 863-866.

Rohner, R. P., \& Khaleque, A. (2010). Testing central postulates of parental acceptance-rejection theory (PARTheory): A meta-analysis of cross-cultural studies. Journal of Family Theory \& Review, 2(1), 73-87. 
Sadri Damirchi, E., Asadi Shishegaran, S., \& Esmaili Ghazivaloii, F. (2016). Effectiveness of Emotion Regulation Training on Cognitive Emotional Regulation, Loneliness and Social Intimacy in Women with Addicted Spouse. Quarterly Journal of Social Work, 5(2), 37-46.

Salimi, M., Mahdavi, A., Yeghaneh, S. S., Abedin, M., \& Hajhosseini, M. (2019). The effectiveness of group based acceptance and commitment therapy (ACT) on emotion cognitive regulation strategies in mothers of children with autism spectrum. Maedica, 14(3), 240-246.

Slavin, R. E. (2019). Educational psychology: Theory and practice.

Sobhigharamaleki, N., Abolghasemi, A., \& Dehghan, H. (2014). Comparison Of A, B, C And D Brain Quadrants Dominance In Normal Students And Students With Learning Disabilities. JOURNAL OF LEARNING DISABILITIES, 3(4), 59-79.

Stevens, R. J., Slavin, R. E., \& Farnish, A. M. (1991). The effects of cooperative learning and direct instruction in reading comprehension strategies on main idea identification. Journal of Educational Psychology, 83(1), 8.

Thghizadeh, M., Ghorbani, T., \& Saffarinia, M. (2015). Effectiveness of emotion regulation techniques of dialectical behavior therapy on emotion regulation strategies in women with borderline personality disorder and substance abuse disorder: Multiple Baseline Design. Journal of Research in PsychologicalHealth, 9(3), 66-73.

Varasteh, M., Aslani, K., \& Amanelahi, A. (2017). Effectiveness of positive parenting program training on parent-child interaction quality. Counseling Culture And Psychotherapy, 7(28), 183-201. 